ISSN. 2775-4324 (Online)

Journal of Physical Activity and Sports

Volume 2, Nomor 2, Agustus 2021, 171-179

Journal of Physical Activity and Sports

\title{
Survei Minat dan Motivasi Klub Bola Basket Fast Kecamatan Kaliwungu Terhadap Kegiatan Olahraga Bola Basket Pada Masa Pandemi Covid 19
}

\author{
Melby Sabila Cahya ${ }^{1}$, Galih Dwi Pradipta ${ }^{2}$ \\ ${ }^{1}$ Pendidikan Jasmani Kesehatan dan Rekreasi. FPIPSKR, Universitas PGRI Semarang, Indonesia \\ * Coressponding Author. E-mail: melby.sabila74@gmail.com
}

\begin{abstract}
The purpose of this study was to determine the interest and motivation of members of the basketball club in Kaliwungu sub-district towards basketball sports activities during the pandemic. The research method used was descriptive quantitative research method with the type of survey research method. The population of this study was the entire fast basketball team in Kaliwungu district using a sample saturated as many as 20 club members. The results showed that the interest of the 20 athletes who became respondents obtained the highest results as many as 11 people $(55 \%)$, the moderate category was 3 people $(15 \%)$, the low category was 5 people $(25 \%)$ and the very low category was 1 person (5). \%), so it can be concluded that most of them have high interest. While the motivation of the 20 athletes who became respondents obtained results in very high categories as many as 3 people (5\%), high category as many as 4 people (20\%), medium category as many as 2 people (10\%), and low category as many as 11 people $(55 \%)$ ), so it is concluded that most of them have low motivation in doing sports, especially basketball during the Covid-19 pandemic. So it can be concluded that the interest of members of the fast basketball club during the Covid 19 pandemic is more due to the desire of members who want to keep exercising in order to maintain immunity body as well as physically so that they can avoid the existing outbreaks, while the motivation of members is still low because members still tend to worry about doing sports activities considering the outbreaks that still occur.
\end{abstract}

Keywords: Interests, Motivation, Basketball

\begin{abstract}
Abstrak
Tujuan penelitian ini ingin mengetahui minat dan motivasi anggota klub bola basket kecamatan kaliwungu terhadap kegiatan olahraga bola basket dimasa pandemi.Metode penelitian yang digunakan yaitu metode penelitian kuantitatif deskriptive dengan jenis metode penelitian survei.Populasi penelitian ini adalah seluruh tim fast bola basket kecamatan Kaliwungu menggunakan sampel jenuh sebanyak 20 anggota klub. Hasil Peneliti menunjukkan bahwa minat dari 20 atlet yang menjadi responden diperoleh hasil tertinggi sebanyak 11 orang (55\%), kategori sedang sebanyak 3 orang (15\%), kategori rendah sebanyak 5 orang (25\%) dan kategori sangat rendah sebanyak 1 orang (5\%), sehingga disimpulkan sebagian besar memiliki minat yang tinggi. Sedangkan motivasi dari 20 atlet yang menjadi responden diperoleh hasil kategori sangat tinggi sebanyak 3 orang $(5 \%)$, kategori tinggi sebanyak 4 orang (20\%), kategori sedang sebanyak 2 orang (10\%), dan kategori rendah sebanyak 11 orang $(55 \%)$, sehingga disimpulkan sebagian besar memiliki motivasi yang rendah dalam melakukan olahraga terutama bola basket selama pandemi Covid-19.Maka dapat disimpulkan bahwa minat anggota klub bola basket fast dimasa pandemi covid 19 ini lebih banyak karena keinginan anggota yang ingin tetap berolahraga agar dapat menjaga imun tubuh serta fisik sehingga dapat terhindar dari wabah yang ada sedangkan motivasi anggota masih rendah karena anggota masih cenderung khawatir untuk melakukan aktivitas olahraga mengingat masih adanya wabah yang terjadi.
\end{abstract}

Kata kunci: Minat, Motivasi, Bola Basket. 


\section{PENDAHULUAN}

Olahraga adalah segala kegitan yang sistematis untuk mendorong, membina, serta mengembangkan potensi jasmani, rohani, dan sosial. Olahraga sangat memerlukan banyak energi untuk melekukan kegiatan olahraga maupun aktivitas lainnya. Aktivitas dalam dunia olahraga sangatlah penting, dikarenakan dapat membuat tubuh kita bias bergerak dan mengeluarkan keringat, sehingga badan kita menjadi sehat dan bugar. Keolahragaan adalah segala aspek yang berkaitan dengan olahraga yang memerlukan pengaturan, pendidikan, pelatihan, pembinaan, pengembangan dan pengawasan (Undang-Undang RI,2005:3).

Olahraga permainan bola basket adalah salah satu olahraga yang memasyarakat yang sangat sering mengadakan kegiatan kejuaraan antar klub, Sekolah Menengah Pertama hingga Perguruan Tinggi. Permainan bola basket adalah salah satu cabang olahraga yang sangat digemari di Indonesia selain sepakbola dan bola voli. Menurut Oliver (2007:6) menyatakan bahwa "bola basket adalah salah satu olahraga paling populer di dunia." Saichudin dan Januarto (1991:43) menjelaskan bahwa olahraga bola basket adalah suatu olahraga permainan yang dimainkan oleh dua regu yang masing-masing regu terdiri dari lima orang. Tiap regu berusaha memasukkan bola ke dalam keranjang/basket regu lawan dan mencegah lawan memasukkan bola atau membuat angka/score, keterampilan bermain bola basket merupakan komponen fundamental dan harus dikuasai oleh setiap pemain, kemampuan atau penampilan seorang pemain bola basket sangat dipengaruhi oleh tingkat penguasaan keterampilan bermain.Dalam memainkan bola basket, pemain dituntut untuk menguasai beberapa teknik dasar bola basket dan juga teknik bermain yang sangat baik. Melempar, mengoper, menggiring, dan memantulkan adalah teknik dasar yang harus dikuasai seorang pemain. Jenis olahraga ini sangat berbeda dengan cabang olahraga lain yang menggunakan bola sebagai objek rebutan. Tidak sama dengan sepak bola, baseball, volley atau bahkan golf (Nidhom Khoeron,2017:2).

Masa pandemi merupakan masa dimana masyarakat diseluruh Indonesia mewajibkan penerapan social distancing. Diwilayah Jawa Tengah beberapa kota sudah banyak yang mengisi aktivitas mereka dengan melakukan olahraga sepertihalnya di kota Kendal tepatnya di kecamatan kaliwungu dimana kecamatan tersebut yang memberikan fasilitas lapangan basket dan tenis, di lapangan basket lebih dominan digunakan berolahraga dengan jumlah pengguna yang cukup banyak dan tidak hanya sehari dalam seminggu melainkan setiap sore lapangan tersebut sering digunakan.

Berdasarkan wawancara yang dilakukan oleh peneliti pada tanggal 19 Agustus dengan anggota klub Fast kecamatan kaliwungu yaitu: Wawancara pertama dengan Riswanda, pada masa pandemi tubuh harus tetap sehat agar terhindar dari berbagai macam virus dan penyakit oleh karena itu dengan melakukan aktivitas olahraga seperti bola basket dapat meningkatkan kekebalan tubuh serta daya tahan imun. Kegiatan olahraga basket ini selalu dilakukan dengan protokol kesehatan yang sudah ada seperti 
sebelum latihan para anggota diwajibkan cuci tangan dengan sabun yang sudah disediakan, bola yang akan digunakan disterilkan terlebih dahulu dengan menyemprotkan disinfektan dan menghindari berjabat tangan dengan mengganti berteput antar siku.

Wawancara kedua dengan Arly, olahraga bola basket merupakan hobi dan dimasa pandemi ini merupakan masa dimana kita sangat-sangat harus menjaga kesehatan tubuh dengan baik oleh karena itu olahraga sangat perlu dilakukan asalkan selalu menerapkan panduan protokol kesehatan dengan tepat.

Tujuan umum dari permainan ini adalah bersifat rekreatif dan sekedar mengisi waktu luang. Namun dalam perkembangannya, tujuan dari permainan bola basket adalah ke pencapaian prestasi, meningkatkan harga diri, dan mengharumkan nama daerah bahkan bangsa dan negara. Pada masa pandemi dimana masyarakat diseluruh Indonesia harus menerapkan social distancing, yang menyebabkan banyak masyarakat mencari kesibukan seperti olahraga bola basket. Oleh karena itu peniliti ingin meneliti penyebab orang-orang tetap melakukan olahraga bola basket di tengah pandemi dimana olahraga ini banyak bersentuhan secara langsung.

\section{METODE}

Metode penelitian yang digunakan yaitu metode penelitian kuantitatif dengan jenis metode penelitian survei. Populasi penelitian ini adalah seluruh tim fast bola basket kecamatan Kaliwungu menggunakan sampel jenuh sebanyak 20 anggota klub. Jenis penelitian dengan pendekatan kuantitatif menggunakan desain deskriptif. Metode analisis data menggunakan analisis mengelompokkan data sesuai variable dan jenis responden, mentabulasi data berdasarkan variable dari seluruh responden, menyajikan data tiap variable yang diteliti, melakukan perhitungan untuk menjawab rumusan masalah, dan melakukan perhitungan untuk menguji hipotesis yang telah diajukan. 


\section{HASIL DAN PEMBAHASAN}

Tabel 1. Hasil Klasifikasi Data Minat Bola Basket

\begin{tabular}{llll}
\hline Interval & Kategori & Frekuensi & Persentase \\
\hline $93 \leq \mathrm{X}$ & Sangat Tinggi & 0 & $0 \%$ \\
\hline $82 \leq \mathrm{X}<93$ & Tinggi & 11 & $55 \%$ \\
\hline $71 \leq \mathrm{X}<82$ & Sedang & 3 & $15 \%$ \\
\hline $61 \leq \mathrm{X}<71$ & Rendah & 5 & $25 \%$ \\
\hline $\mathrm{X}<61$ & Sangat Rendah & 1 & $5 \%$ \\
\hline Total & & 20 & $100 \%$ \\
\hline
\end{tabular}

Sumber : Data primer penelitian yang diolah (2020)

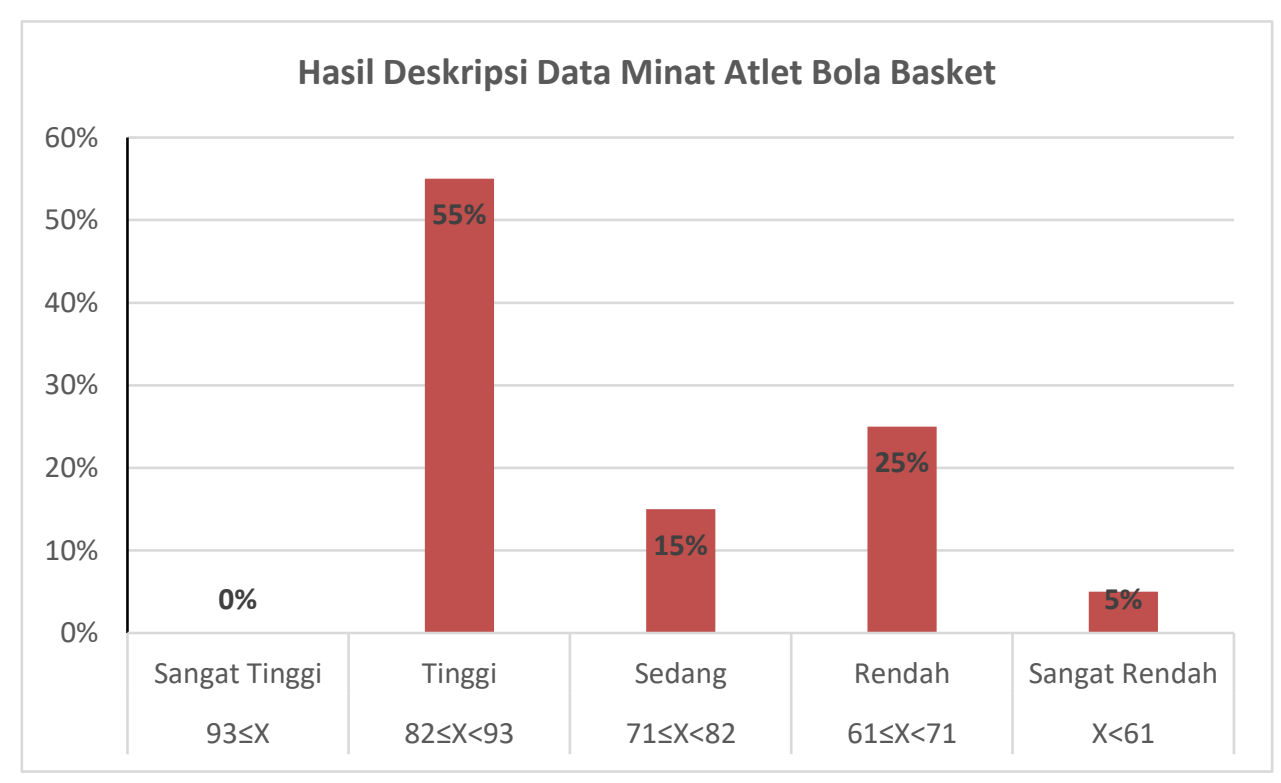

Gambar 1. Grafik Deskripsi Data Minat Atlet Bola Basket di Klub Fast Kaliwungu Kendal

Berdasarkan hasil perhitungan pada Tabel 1, diperoleh hasil bahwa minat atlet bola basket di klub Fast Kaliwungu yang termasuk dalam kategori tinggi sebanyak 11 orang (55\%), kategori sedang sebanyak 3 orang (15\%), kategori rendah sebanyak 5 orang (25\%) dan kategori sangat rendah sebanyak 1 orang $(5 \%)$. Sehingga dapat disimpulka bahwa sebagian besar atlet bola basket di club Fast memiliki minat yang tinggi dalam melakukan olahraga terutama bola basket selama pandemi Covid-19. 
Tabel 2. Hasil Klasifikasi Data Motivasi Bola Basket

\begin{tabular}{llll}
\hline Interval & Kategori & Frekuensi & Persentase \\
\hline $79 \leq \mathrm{X}$ & Sangat Tinggi & 3 & $15 \%$ \\
\hline $70 \leq \mathrm{X}<79$ & Tinggi & 4 & $20 \%$ \\
\hline $60 \leq \mathrm{X}<70$ & Sedang & 2 & $10 \%$ \\
\hline $50 \leq \mathrm{X}<60$ & Rendah & 11 & $55 \%$ \\
\hline $\mathrm{X}<50$ & Sangat Rendah & 0 & $0 \%$ \\
\hline Total & & 20 & $100 \%$ \\
\hline
\end{tabular}

Sumber : Data primer penelitian yang diolah (2020)

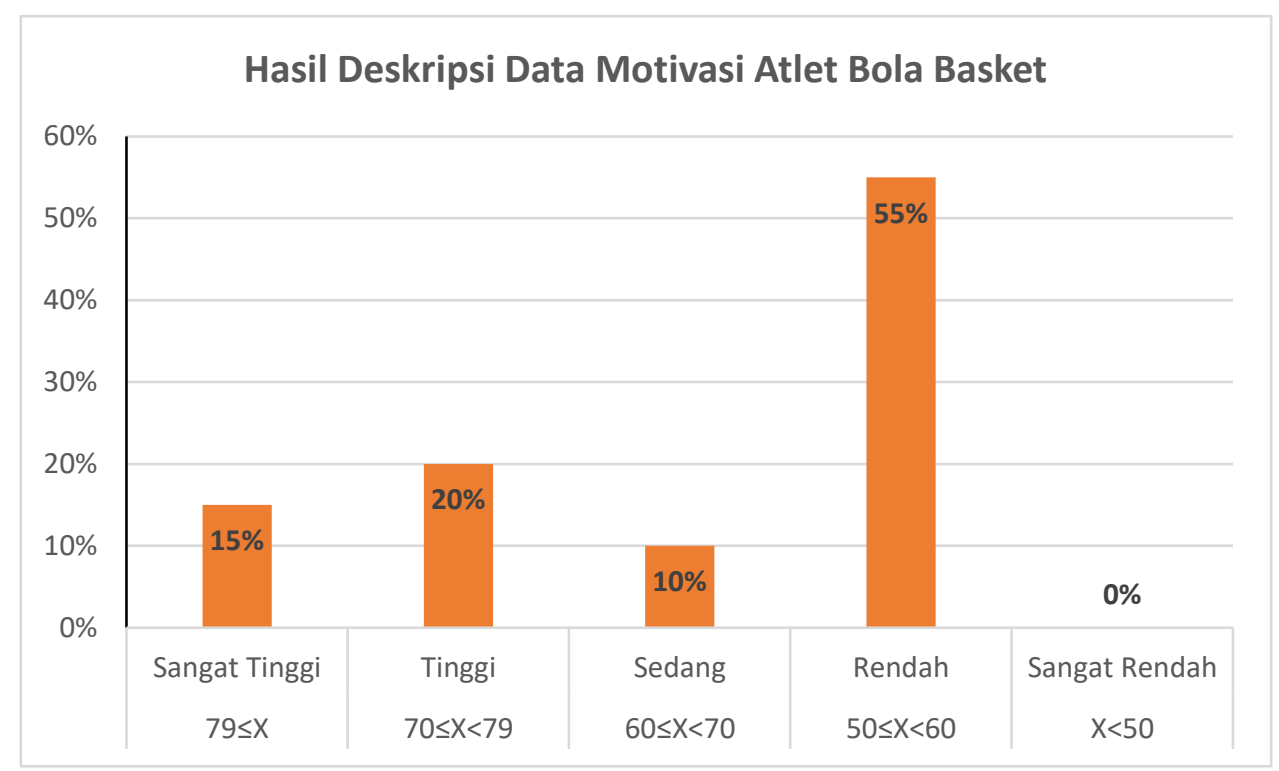

Gambar 2. Grafik Deskripsi Data Motivasi Atlet Bola Basket di Klub Fast Kaliwungu Kendal

Berdasarkan hasil perhitungan pada Tabel 2, diperoleh hasil bahwa motivasi atlet bola basket di klub Fast Kaliwungu yang termasuk dalam kategori sangat tinggi sebanyak 3 orang (5\%), kategori tinggi sebanyak 4 orang (20\%), kategori sedang sebanyak 2 orang (10\%), dan kategori rendah sebanyak 11 orang (55\%). Sehingga dapat disimpulka bahwa sebagian besar atlet bola basket di klub Fast memiliki motivasi yang rendah dalam melakukan olahraga terutama bola basket selama pandemi Covid19. 


\section{KESIMPULAN}

Berdasarkan rumusan masalah dan hasil penelitian tentang minat dan motivasi klub bola basket fast kaliwungu terhadap kegiatan olahraga bola basket pada masa pandemi Covid 19 maka dengan ini disimpulkan : Minat atlet bola basket di klub fast di kecamatan Kaliwungu Kendal pada masa pandemi covid 19, dari 20 atlet sebagai responden diperoleh hasil kategori tinggi sebanyak 11 orang (55\%), kategori sedang sebanyak 3 orang (15\%), kategori rendah sebanyak 5 orang $(25 \%)$ dan kategori sangat rendah sebanyak 1 orang (5\%). Sedangkan motivasi atlet bola basket di klub fast di kecamatan Kaliwungu Kendal pada masa pandemi covid 19, dari 20 atlet sebagai responden diperoleh hasil kategori sangat tinggi sebanyak 3 orang (5\%), kategori tinggi sebanyak 4 orang (20\%), kategori sedang sebanyak 2 orang (10\%), dan kategori rendah sebanyak 11 orang (55\%).

Dengan kesimpulan Minat atlet di klub Fast kecamatan kaliwungu pada masa pandemi covid 19 lebih tinggi karena selama pandemi Covid-19, besar dari mereka lebih banyak dirumah baik work from home maupun study from home. Sehingga lebih banyak waktu untuk melakukan olahraga khususnya bola basket. Dimana selama pandemi Covid-19 dibutuhkan olahraga yang cukup agar daya tahan tubuh terjaga. Sedangkan motivasi untuk olahraga bola basket rendah pada masa pandemi covid 19 karena adanya social distancing (pembatasan social) sehingga para atlet merasa harus jaga jarak dalam berkegiatan , dimana olahraga bola basket merupakan olahraga beregu yang dimainkan lebih dari 2 orang. Sehingga harus sesuai dengan protokol kesehatan sebelum melakukan olahraga bola basket. Berdasarkan penelitian yang dilakukan, arsan yang bisa diberikan yaitu :

\section{Bagi Pelatih}

Agar dapat memberikan motivasi lebih pada anggota dan memberikan standar latihan khusus agar dapat menarik minat serta mendukung anggota klub supaya terus berlatih walaupun dimasa pandemi covid 19 ini dengan tetap menerapkan sesuai protokol kesehatan.

\section{Bagi Anggota Klub}

Sebagai pengetahuan kepada anggota klub tentang minat dan motivasi berolahraga dimasa pandemi covid 19.

\section{Bagi Peneliti}

Sebagai acuan dan pengetahuan tentang minat dan motivasi berolahraga dimasa pandemi covid 19 serta wawasan bagi peneliti-peneliti lain. 


\section{Bagi Universitas}

Sebagai wacana maupun menambah pengetahuan dan wawasan minat dan motivasi berolahraga khususnya dimasa pandemi covid 19 di bidang bola basket.

\section{DAFTAR PUSTAKA}

Andi, M. (1982). Psikologi Remaja. Surabaya : Usaha Nasional.

Ahmadi, N. (2007). Permainan Bola Basket. Surakarta : Era Intermedia.

Ariyanto, S. (2016). Motivasi Olahraga Rekreasi Pada Pengunjung Desa Wisata Kampoeng Djowo Sekatul Kecamatan Limbangan Kabupaten Kendal Tahun 2016. Kendal: Universitas Negeri Semarang.

Armi, dkk. (2015). "Partisipasi orang tua terhadap minat anak berolahraga di kecamatan singkil kabupaten Aceh Singkil". Jurnal Ilmiah Mahasiswa Pendidikan Jasmani, Kesehatan Dan Rekreasi Fakultas Keguruan Dan Ilmu Pendidikan Unsyiah. 1 (11), 258-271.

Aryanto, B. (2018). Teknik dan Taktik Dalam Permainan Bola Basket. Yogyakarta: UNY Press.

Deni, M. (2017). "Hubungan dukungan orang tua siswa dengan motivasi siswa dalam mengikuti sekolah sepak bola (SSB)". Biormatika Jurnal Ilmiah FKIP Universitas Subang. 3 (2) 2461-3961.

Djamarah, B.S. (2008). Psikologi Belajar. Jakarta: Rineka Cipta.

Eka, A \& Pudjijuniarto. (2016). "Motivasi mahasiswi Unesa dalam mengikuti olahraga futsal di UKM Universitas Negeri Surabaya". E-Journal Kesehatan Olahragas Vol. 06 (2) 650-653.

Fahmi, dkk. (2018). "Minat dan motivasi siswa mengikuti ekstrakurikuler beladiri pencak silat di SMP/MTs negeri se-kecamatan Gubug Kabupaten Grobogan". Journal of Physical Education Sport Health and Recreations (online). Vol. 1. No. 1 (diakses 2 April 2019).

Fathirrahman, A. (2019). Survei Minat dan Motivasi Permainan Bola Basket Pada Siswa SMK Kartika XX-1 Makassar. Makassar: Universitas Negeri Makassar. Tidak diterbitkan.

Iwan, dkk. (2016). "Motivasi berlatih atlet ukm kempo Unsyiah Tthun 2015". Jurnal Ilmiah Pendidikan Jasmani, Kesehatan Dan Rekreasi. 2 (2) 125-135.

Jon Oliver. (2007). Dasar-Dasar Bola Basket. Bandung: Human Kinetics.

Karel, M. (2015). “Analisis motivasi berprestasi ttlet pusat pendidikan dan latihan olahraga pelajar ( PPLP ) provinsi Nusa Tenggara Timur”. Jurnal Kebijakan \& Administrasi Publik. 19 (2) 105-113. 
Komarudin, (2017). Psikologi Olahraga, Bandung: PT Remaja Rosdakarya.

Kurniadi, S \& Hamdani. (2018). "Identifikasi penyebab kurangnya minat siswa terhadap ekstrakulikuler pencak silat di SMA Negeri 1 Cerme". Jurnal Pendidikan Olahraga Kesehatan Unesa. 06 (03) 603-607.

Kurniandani, I. (2019). Pengaruh Pembelajaran Jigsaw dan Problem Based Learning dalam Meningkatkan Hasil Belajar Lay Up Bola Basket Kelas X SMA N 8 Semarang. Skripsi: Semarang: Universitas PGRI Semarang.

Kusuma B, A. \& Setyawati, H. (2016). "Survei factor-faktor yang mempengaruhi minat olahraga rekreasi akhir pekan di alun-alun Wonosobo". Journal of Physical Education, Sport, Health and Recreation. 5 (2) 67-73.

Lestari, M. A. (2019). "Minat pelajar putri SMA se-Kecamatan Teluk Keramat pada kompetisi sepak bola di Kabupaten Sambas". Jurnal Pendidikan Jasmani FKIP Untan Pontianak. 03 (1) $1-10$.

Martaningtyas, A. (2019). Minat dan Motivasi Atlet Junior dalam Mengikuti Latihan Tarung Derajat di Satlat Se Karesidanan Semarang Tahun 2019. Semarang: Universitas Semarang.

Mikanda, R. (2014). Buku Super Lengkap Olahraga. Jakarta: Dunia Cerdas.

Muhajir. (2007). Pendidikan Jasmani Olahraga Dan Kesehatan. Bandung: Yudistira.

Nidhom, K. 2017. Buku Pintar Basket. Jakarta Timur: Anugrah.

Nur, C \& Cahyo, D. (2017). "Minat siswa MTS N 1 Paron Ngawi pada kegiatan ekstrakulikuler bola basket”. Jurnal Pendidikan Olahraga dan Kesehatan. 5 (2) 291-296.

Perbasi. (2010). "Peraturan Permainan Bola Basket.” Jakarta.

Pratama, J. A. (2014). "Motivasi-motivasi yang sama pada anak dalam mengikuti klub bola basket Trikarya Warrior Krian Kabupaten Sidoarjo”. Jurnal Kesehata Olahrgara. 2 (3) 166-178.

Rifai, A \& Anni, C.T. (2016). Psikologi Pendidikan. Semarang: UNNES Press.

Rosalia, H. (2019). Faktor-faktor Yang Mempengaruhi Minat Olahraga Rekreasi Akhir Pekan di Aun - Alun Kabupaten Tegal Tahun 2019. Tegal: Universitas Negeri Semarang.

Sardirman, (2011). Interaksi dan Motivasi Belajar Mengajar, Jakarta: PT Rajagrafindo.

Sodikin, C. dkk. (2010). Pendidikan Jasmani Olahraga Dan Kesehatan Untuk SMA/SMK. Jakarta: Pusat Pembukuan Kementerian Pendidikan Nasional.

Sugiyono. (2015). Metode Penelitian dan Pengembangan(Research and Development)/R\&D). Bandung: ALFABETA.

Sugiyono. (2017). Metode Penelitian Pendidikan (Pendekatan Kuantitatif, Kualitatif, dan R \& D). Bandung: ALFABETA.

Tomi, A., \& Yudasmara, D. S. (2020). "Survei pembinaan ekstrakurikuler bola basket pada peserta didik sekolah menengah atas. Jurnal Sport Science and Health. 2 (1) 32-38. 
Winda, dkk. (2020). "Survei pembinaan ekstrakurikuler bola basket di SMA Negeri sekecamatan Lowokwaru Kota Malang”. Jurnal Sport Science and Health Vol. 2 (1) 3238 . 